\title{
EDITORIAL
}

\section{Peter Howard leaves the European Journal}

\author{
E. Berglund
}

Peter Howard has played a major part in the success of this Journal. He has been the Managing Editor from its start in 1988.

In 1983, the Bulletin Européen de Physiopathologie Respiratoire became the official journal of the European Society for Clinical Respiratory Physiology (SEPCR) and Peter Howard took over the management. Until then, the journal had been managed and printed by a publishing company at an enormous price. A substantial part of the cost had been covered by research grants, which were no longer available. Peter Howard cleaned up the affairs of the journal and moved the technical editing to an office in his home. From then on, Peter has advocated that the most effective way to manage a journal is to "do it yourself".

The next step was to suggest merging the Bulletin with the European Journal of Respiratory Diseases, a journal owned by the Munksgaard Publishing Company but without society affiliation. The editors of both journals were enthusiastic, more so than the publishing company. They realized that only a strong European respiratory journal could in any way compete with the American journals. They also wished to bring together the two European respiratory societies.

In the negotiations with the Munksgaard directors, Peter Howard, following his conviction of "do it yourself" insisted that a great part of the production of the new journal should be in the hands of the SEPCR, i.e. in the Sheffield office. He also expressed opinions about how to perform the technical editing with the use of modern technology. I dare say that, in the beginning, the Munksgaard representatives were very sceptical. When the agreement was finally signed in 1987, the whole production task was handed over to Peter Howard.

A look at the European Respiratory Journal will show that Peter and his staff have managed the journal in a superb way, with imagination and technical skill combined. The cover of the journal was chosen by Peter, and slight modifications of this cover are now used for the European Respiratory Review and the European Respiratory Topic. The setting of the Abstracts, together with information about the authors was Peter's doing. The technical editing was initially carried out in Peter's home office, but with the expansion of the journal, a separate office has been acquired. Peter's staff have managed to use advanced computer programs without hiring expensive consultants. The technical quality of the journal has gradually improved. Every time I have visited the Sheffield office, I have been impressed.

The merging of the two journals into the European Respiratory Journal, belonging to SEPCR led to the merging of the two European respiratory societies into the European Respiratory Society. The progress and the success of both the Journal and the Society have been remarkable. We owe this in large part to Peter Howard. 